\title{
A study of volatility risk
}

\author{
Kalai Lamia*, Jilani Faouzi \\ Graduate Institute of Business and Accounting of Bizerta, University of Carthage, University of Tunis El Manar, Faculty of economic \\ Sciences and Management of Tunisia
}

\section{Email address:}

lamiakalai@yahoo.fr (K. Lamia), faouzi.jilani@fsegt.rnu.tn (J. Faouzi)

\section{To cite this article:}

Kalai Lamia, Jilani Faouzi. A Study of Volatility Risk. Journal of Finance and Accounting. Vol. 2, No. 1, 2014, pp. 1-10. doi: 10.11648/j.jfa.20140201.11

\begin{abstract}
Time variations of market volatility considerably affect investments risk evaluation and prediction of future returns. They are presented as a source of systemic risk to which is added a risk related to stocks' sensitivity to volatility shocks. Analysis of the relationship between stocks volatility and market volatility allows for determining whether stocks' sensitivities to volatility shocks may estimate market's future risk price. Volatility shocks are defined in terms of volatility risk hedging factors, when market volatility risk price is high and for stocks that are positively correlated to these hedging factors, the value of returns is expected to be low. Idiosyncratic volatility is on the other hand a variable omitted from volatility total risk. If market volatility risk is a missing component of systematic risk, standard models should mis-price portfolios sorted by idiosyncratic volatility because these models do not include factor loadings measuring exposure to market volatility risk.
\end{abstract}

Keywords: Volatility Shocks, Risk Factors, Hedging Factors, Systemic Volatility, Idiosyncratic Volatility

\section{Introduction}

Stocks volatility varies in time. A number of studies examined the relationship between market volatility and stocks returns. However, the question on how volatility affects stocks received less attention by the literature [1], [2].

Time variations of market volatility affect considerably investment risk evaluation and prediction of future returns. They are presented as a source of systemic risk to which is added a risk related to stocks' sensitivity to volatility shocks.

Our study consists first in analysing the relationship between stocks volatility and market volatility in order to determine whether exposure to volatility risk allows for estimating market volatility's future risk price. Building up investment portfolios with different sensitivity degrees to market innovations should show whether volatility risk price is negative and whether stocks with positive and high sensitivity to volatility risk should yield low future returns. Several financial theories explain why volatility risk price should be negative. Campbell and Henschell (1992), indicate that investors look for covering themselves against risk in periods of volatility variations, which generally coincide with a market's downward movement and deterioration of investment opportunities. They buy stocks with the lowest sensitivity to volatility risk whose evaluation may be done through different risk factors. The pioneering work [1],[2],[3] indicate that stocks with the highest sensitivity to volatility are stocks that cover against a downward market risk. Increasing demand of these stocks for the highest systemic volatility increases their prices and decreases their average returns. The evidence in [4] relates this trend to coskewness. The authors show that when volatility increases, stocks with decreasing rates are the stocks whose returns are negatively skewed in contrast to stocks whose rates increase and accumulate positively skewed returns.

With reference to these studies, our study examines the relationship between risk fluctuations and stocks' different degrees of exposure to volatility shocks.

The aim of this paper is to estimate stocks sensitivity to volatility shocks in terms of the component "idiosyncratic volatility" expressed through residuals of Fama and French model [5]. We proceed as follows: if idiosyncratic volatility is a risk factor orthogonal to other risk factors, stocks sensitivity to idiosyncratic volatility should be taken into account and the firms that are the most sensitive to market volatility should display higher idiosyncratic volatility. Earlier researchers find a significantly positive relation between idiosyncratic volatility and average returns, For example, [6] shows that idiosyncratic volatility carries a positive coefficient in cross-sectional regressions.[7] find that portfolios with higher idiosyncratic volatility have 
higher average returns, but they do not report any significance levels for their idiosyncratic volatility premiums. On the other hand, [8] finds that a cross-sectional regression coefficient on total variance for size-sorted portfolios carries an insignificant negative sign.

The goal of this paper is to determine whether the volatility of the market is a priced risk factor, to estimate the price of aggregate volatility risk and to examine the relationship between idiosyncratic volatility and expected returns, where idiosyncratic volatility is defined relative to the standard Fama and French (1993) model

Our paper is then structured as follows: the second section studies volatility risk and evaluates stocks' different sensitivity degrees to this risk using innovation parameters as well as volatility hedging factors. The third section presents idiosyncratic volatility and defines it as a determining factor of the global risk of market volatility.

\section{Volatility Risk}

\subsection{Stocks Sensitivity to Volatility Innovations}

In this paper, we examine the relationship between stocks future returns and stocks sensitivity to volatility innovations in the Tunis Stock Market, over a period stretching from $1 / 1 / 1999$ to $15 / 06 / 2011$. The examined period features a reform plan that displays different episodes of stocks fluctuations (growth, crisis, recovery ...) and interesting circumstances to analyse in depth volatility characteristics.

Data used are daily frequencies. The selected sample includes 30 listed firms, selected from a common and balanced data base of the set of stocks.

The used Tunindex is a synthetic index of the Tunis stock market. The index's value is given by the stocks' arithmetic mean, comparing the weighted index to their market capitalisation. The rate that is used to determine this index is either the closing rate or the exceeded reserve threshold.

Our study suggests that idiosyncratic volatility should be positively linked to forward returns where risk-averse investors ask for a premium to compensate stocks' detention risk of which volatility risk is considerable

We examine volatility risk using average returns variations of stocks with different sensitivity to volatility innovations. Volatility innovation parameter is defined by VIX which represents Tunindex's variations at dates $t$ and $\mathrm{t}+1\left(v_{t}-v_{t+1}\right)$. Our model takes then the following form:

$$
r_{t}^{i}=\beta_{0}+\beta_{M K T}^{i} \cdot M K T+\beta_{\Delta V I X}^{i} \cdot \Delta V I X+\xi_{t}
$$

With $M K T$ : market risk represented by a return surplus $\triangle V I X:$ volatility innovation; $\beta_{M K T}^{i}$ and $\beta_{\Delta V I X}^{i}$ : respectively sensitivity of stocks to market risk and volatility risk

To study evolution of stocks' volatility risk, we specify observable market and volatility risk variables.

Our estimation covers regular and enough stretched time intervals. Then, our daily data is estimated over a month.
This choice is explained by the fact that under low-frequency effect of volatility innovations is more important and allows for estimating unpredictable market variations. Our estimation procedure follows the following steps. We determine the values of $\beta_{\Delta V I X}^{i}$ estimated at the beginning of each month and for each portfolio. The choice of investment portfolios is based on firms whose sensitivity to market volatility is enough high. In particular, we focus on the variations of $\Delta$ VIX constructed by means of the daily data of stocks during a month. At the end of each month, the stocks are classified into portfolios using the coefficient of sensitivity to volatility risk $\beta_{\Delta V I X}^{i}$. Thus, firms belonging to the 1 st portfolio are firms with the lowest $\beta_{\Delta V I X}^{i}$ coefficient while firma belonging to the 5 th portfolio are firms with the highest $\beta_{\Delta V I X}^{i}$ coefficient.

Descriptive statistics of the different investment portfolios are presented in Table (1). The first two columns represent respectively the mean and standard deviation of portfolios returns. We notice that because portfolios are classified according to their sensitivity to volatility risk, the value $\beta_{\Delta V I X}^{i}$ is increasing and monotone. It is -7.26 for the first portfolio and 5.4 for the fifth. We notice that the mean return value of these portfolios decreases when $\beta_{\Delta V I X}^{i}$ increases, with a significant monthly difference of 0.16 between portfolios with the highest $\beta_{\Delta V I X}^{i}$ and those with the lowest $\beta_{\Delta V I X}^{i}$.

\subsection{Hedging Factors of Volatility Risk}

Volatility risk is defined in terms of hedging factors of volatility risk $F V X$ estimated through an investment portfolio consisting of stocks highly correlated with volatility innovations. The regression is defined by:

$$
\Delta V I X_{t}=c+b^{\prime} X_{t}+\mu_{t}
$$

Where $X_{t}$ represents surplus of stocks returns;

$b^{\prime} X t$ is factor FVIX which represents market volatility risk ; coefficient $b$ ' represents weight of a portfolio with zero cost.

Estimation of $b$ ' by regression (2) aims at constituting the hedging factors of monthly volatility risk. Once FVIX is obtained, our estimation model is represented by the regression:

$$
r_{t}^{i}=\alpha_{i}+\beta_{M K T}^{i} \cdot M K T+\beta_{F V I X}^{i} \cdot F V I X+\xi_{t}
$$

With $M K T$ : market risk

FVIX: hedging factors of volatility;

$\beta_{M K T}^{i}$ and $\beta_{F V I X}^{i}:$ are respectively stocks sensitivity to market risk and to volatility risk.

Then, the aim of our study is to show the presence of a linear relationship between hedging factors of volatility risk and stocks mean returns. Thus, when market volatility risk is 
high and for the stocks that are positively correlated to FVIX, the value of $r_{i}^{t}$ is expected to be low.

Column 2 of Table (1) reports the estimated values of $\beta_{F V I X}^{i}$ for the portfolios classified in terms of past $\beta_{\Delta V I X}^{i}$. We notice that for portfolio 1 the value of $\beta_{F V I X}^{i}$ is -7.9 while it is 5.4 for portfolio 3 . Sensitivity between volatility risk and stocks mean returns is then validated. However, we point out that these results are similar to those obtained for volatility innovation $\triangle V I X$ where $\beta_{\Delta V I X}^{i}$ is -6.9 for portfolio 1 and 4.9 for portfolio 5 .

\subsection{Integration of Risk Factors}

Our study consists in estimating the ex-post value of stocks sensitivity to volatility innovations $\beta_{\Delta V I X}^{i}$ after a month of investments portfolio creation.

Table (1) reports the obtained results. We notice that the ex-post $\beta_{\Delta V I X}^{i}$ is monotone and increasing. It is -6.11 for portfolio 1 and 6.5 for portfolio 5 . We notice as well that the deviation between the two portfolios remains low enough.

To estimate portfolios returns, we evaluate ex-post volatility risk factors of FVIX and we integrate these values in addition to the three FF factors. Our regression is then written as follows:

Table (1). Portfolios classified in terms of their exposure degree to volatility shocks

\begin{tabular}{ccccccccccc}
\hline $\mathbf{P}$ & $\begin{array}{c}\text { Mean } \\
\mathbf{( * 1 0 0 )}^{\mathbf{1 0}}\end{array}$ & $\begin{array}{c}\text { Standard } \\
\text { Déviation }\end{array}$ & $\mathbf{B M}$ & $\begin{array}{c}\text { CAPM } \\
\text { Alpha }\end{array}$ & $\begin{array}{c}\text { FF-3 } \\
\text { Alpha }\end{array}$ & $\beta_{\Delta V I X}^{i}$ & $\beta_{F V I X}^{i}$ & $\beta_{\Delta V I X}^{i}$ & $\beta_{F V I X}^{i}$ \\
\hline $\mathbf{1}$ & 0,0319 & 0,003 & 0.734 & $0.0231^{\mathbf{b}}$ & $0.0463^{\mathbf{b}}$ & $-7,269$ & -6.987 & $-6,119$ & -7.908 \\
$\mathbf{2}$ & 0,0417 & 0,005 & 0.655 & $0.0520^{\mathbf{b}}$ & $0.0765^{\mathbf{b}}$ & $-0,969$ & -4.546 & $-0,326$ & -3.985 \\
$\mathbf{3}$ & 0,0958 & 0,004 & 0.343 & $0.072^{\mathbf{b}}$ & $0.0574^{\mathbf{b}}$ & 2,2875 & 1.2435 & $-1,904$ & -2.607 \\
$\mathbf{4}$ & 0,0241 & 0,003 & 0.244 & $0.0871^{\mathbf{b}}$ & $0.0987^{\mathbf{b}}$ & 3,2565 & 3.8796 & 2,015 & 3.002 \\
$\mathbf{5}$ & 0,0174 & 0,003 & 0.421 & $0.1867^{\mathbf{b}}$ & $0.0976^{\mathbf{b}}$ & 5,4006 & 4.9877 & 6,531 & 2.897 \\
$\mathbf{5 - 1}$ & $-0,0142$ & & & 0,1636 & 0,0513 & & & & & \\
\hline
\end{tabular}

$$
r_{t}^{i}=\alpha_{i}+\beta_{M K T}^{i} \cdot M K T+\beta_{S M B}^{i} S M B+\beta_{H M L}^{i} H M L+\beta_{F V I X}^{i} \cdot F V I X+\xi_{t}^{i}
$$

Where the first three factors MKT, SMB, HML are the factors of market, size and book to market ratio. Values of $\beta_{\text {FVIX }}^{i}$ are determined through portfolios of firms classified in terms of $\beta_{\Delta V I X}^{i}$.

The results are reported in Table (1). We notice that during the post-creation period, $\beta_{F V I X}^{i}$ is significant and increasing. It is -7.9 for portfolio 1 and 2.8 for portfolio 2 . The obtained results draw us to conclude that conditioned by stocks sensitivity to volatility innovation, there is a significant difference between stocks returns that are estimated by considering risk factors of market, size and book to market ratio.

\subsubsection{Portfolio Creation Period}

We showed previously that for a month-long study period, the obtained results remain inconclusive. We therefore mend for this limitation by extending the portfolios pre-creation period from 1 to 3 and 12 months.

In table (2), we notice that extending portfolios pre-creation period considerably improves the results. For a 3 -month pre-creation period, the $\alpha$ of the FF model is 0.007 for the fifth portfolio with a t-statistic of 5.7 for a 3 -month study period and 0,005 with a t-statistic of 4.9 for a 1 -month study period. When pre-creation period reaches 12 months, the fifth portfolio scores an $\alpha$ of the FF model equal to 0.01 and a t-statistic of 1.78 .

Table 2. Characteristics of portfolios created in terms of $\beta_{\Delta V I X}^{i}$

Panel A. Study of the different portfolios pre-creation periods

\begin{tabular}{|c|c|c|c|c|c|c|}
\hline \multirow[b]{2}{*}{ pre-creation periods } & \multicolumn{6}{|c|}{$\beta_{\Delta V I X}^{i}$} \\
\hline & 1 & 2 & 3 & 4 & 5 & $5-1$ \\
\hline 1 month & $\begin{array}{l}0.0065 \\
(2.887)\end{array}$ & $\begin{array}{c}0.006 \\
(3.007)\end{array}$ & $\begin{array}{c}0.008 \\
(3.224)\end{array}$ & $\begin{array}{l}0.0088 \\
(2.466)\end{array}$ & $\begin{array}{l}0.0076 \\
(5.785)\end{array}$ & 0,0011 \\
\hline 3 month & $\begin{array}{l}0.0013 \\
(2,430)\end{array}$ & $\begin{array}{l}0.0021 \\
(2,703)\end{array}$ & $\begin{array}{c}0.003 \\
(2,665)\end{array}$ & $\begin{array}{l}0.0076 \\
(0,576)\end{array}$ & $\begin{array}{l}0.0055 \\
(4,923)\end{array}$ & 0,4002 \\
\hline 12 month & $\begin{array}{l}-0.004 \\
(-3,76)\end{array}$ & $\begin{array}{l}-0.002 \\
(-1.44)\end{array}$ & $\begin{array}{l}-0.0052 \\
(-1.983)\end{array}$ & $\begin{array}{c}0.0001 \\
(1.5703)\end{array}$ & $\begin{array}{l}0.0018 \\
(1.785)\end{array}$ & 0,0062 \\
\hline
\end{tabular}


Panel B. Study of size and BM effect

\begin{tabular}{ccccc}
\hline & \multicolumn{2}{c}{ All firms } & \multicolumn{2}{c}{ Excluding the smallest and with the most important BM firms } \\
Portfolios & Mean $(* 100)$ & Standard Deviation & Mean $(* 100)$ & Standard Deviation \\
\hline 1 & 0,0544 & 0,00303 & 0.00241 \\
2 & 0.02802 & 0.06393 & 0.00463 & 0.00677 \\
3 & 0.0199 & 0.00460 & 0.00201 & 0.00571 \\
4 & 0.0238 & 0.00373 & 0.00259 \\
5 & 0.017 & 0.00331 & 0.00139 \\
$5-1$ & -0.022 & & -0.00102 \\
\hline
\end{tabular}

Panel C. Study of the Momentum effect

\begin{tabular}{|c|c|c|c|c|c|c|}
\hline Portfolios & Mean (*100) & $\begin{array}{l}\text { Standard } \\
\text { Deviation }\end{array}$ & CAPM Alpha & FF-3 Alpha & Pre-creation $\beta_{\Delta V I X}^{i}$ & Post-creation $\beta_{F V I X}^{i}$ \\
\hline 1 & -0.0262 & 0.005323 & $\begin{array}{c}-0,00285 \\
(-1,384)\end{array}$ & $\begin{array}{c}-0.0027 \\
(-1.4156)\end{array}$ & $-3,1196$ & -7.876 \\
\hline 2 & 0.0462 & 0.00381 & $\begin{array}{l}0.00331 \\
(2.7079)\end{array}$ & $\begin{array}{c}0.00311 \\
(2,7063)\end{array}$ & $-2,3269$ & -3.332 \\
\hline 3 & 0.0131 & 0.00421 & $\begin{array}{l}0.00098 \\
(0.0644)\end{array}$ & $\begin{array}{c}0.0001 \\
(0.0071)\end{array}$ & $-1,67504$ & -2.5649 \\
\hline
\end{tabular}

With these results, we may conclude that the effect of $\beta_{\Delta V I X}^{i}$ increases when portfolios pre-creation period increases. This may be explained by time variations of market sensitivity to volatility innovations. The more restrained and limited the pre-creation period and the conditional estimation of $\beta_{\Delta V I X}^{i}$, the lower the difference between portfolios returns (3-1). One-month span results report more significant estimations.

\subsubsection{Size and Book-to-Market Ratio (BM)}

It is often admitted that small-sized growing firms are the most competitive firms when market volatility increases. Then, we propose to study the effect of volatility variations on this type of firms and the market in order to check for the effect of size and BM on portfolios mean returns, classified in terms of $\beta_{\Delta V I X}^{i}$. To this end, we exclude from the studied portfolios the smallest and with the most important BM firms and we reclassify the firms in new portfolios. Examining the mean and standard deviation of the portfolios surplus returns, we notice that the difference between average monthly returns between portfolios 5 and 1 is - 0,002. A result which indicates that stocks sensitivity to volatility bears on two risk factors: size and BM.

\subsubsection{The Momentum Effect}

To study momentum effect, we create two stock portfolios classified in terms of mean returns of the past 12 months and $\beta_{\Delta V I X}^{i}$ value. Computing the difference of mean returns between low-sensitivity portfolios $\beta_{\Delta V I X}^{i}$ and portfolios with high $\beta_{\Delta V I X}^{i}$ values is 0,003 per month. Values of $\alpha$ for CAPM and the FF model in order to take into account the momentum effect indicate that the differences between portfolios (3-1) are significant. The value of $\beta_{\Delta V I X}^{i}$ is increasing and monotone. It increases from portfolio 1 to portfolio 3. These results allow us to conclude that the momentum effect allows for taking into account stocks sensitivity to volatility risk.

\subsection{Volatility Risk Price}

We have shown previously that low returns of highly-sensitive stocks to volatility risk cannot be explained uniquely by factors like size, BM or momentum effects, although they display an important difference in hedging factor of volatility risk FVIX.

Our next procedure then consists in estimating volatility risk price by including the variables likely to explain returns variations, in addition to MKT which represents market risk and hedging factors of volatility risk FVIX.

In order to estimate hedging factors premiums noted by $\lambda$ FVIX, we run a series of tests where stocks are classified in terms of $\beta_{M K T}^{i}$ and $\beta_{F V I X}^{i}$. Classifying those stocks in terms of $\beta_{M K T}^{i}$ is made possible thanks to regressing for each month stocks returns surplus in terms of market returns surplus.

Stocks are first classified into portfolios in terms of $\beta_{M K T}^{i}$, then each portfolio is divided in itself into sub-portfolios in terms of $\beta_{F V I X}^{i}$. At this level of estimation, volatility risk price is integrated along with risk factors likely to affect forward stocks returns. Our specification includes then the three factors of the FF model as well as the momentum effect. 


$$
r_{t}^{i}=\alpha_{i}+\beta_{M K T}^{i} \cdot \lambda_{M K T}+\beta_{F V I X}^{i} \cdot \lambda_{F V I X}+\beta_{S M B}^{i} \cdot \lambda_{S M B}+\beta_{H M L}^{i} \cdot \lambda_{H M L}+\beta_{U M D}^{i} \cdot \lambda_{U M D}+\xi_{t}
$$

Where $\lambda_{i}$ represents premium of the different risk factors; In this stydy, we select a sample of 30 stocks and first we estimate $\beta_{M K T}$ for the entire sample. Estimating risk factors premiums $\lambda_{i}$ is then done for the different portfolios using Fama, Mac Beth model [7]. Panel A of Table (6) reports the obtained results. With equation I, we estimate market risk premium in addition to FVIX factor. Equation II includes the three factors of the FF model. Equation III includes in addition to market factors, size, BM and the momentum effect (UMD).

In Panel B, we study ex-post factors of volatility risk FVIX and risk premiums obtained from equation I. The results of Panel A draw our attention to the fact that risk factors premiums are not all significant. Moreover, HML premiums score negative values at regression II, which reflects that the BM effect poorly explain volatility risk during the study period. For volatility risk price FVIX, this factor is $-2.19 /$ month. This result is statistically significant at the 5\% level. By integrating the three factors in regression III, volatility risk price exceeds -2.09 . This negative value allows us to validate the hypothesis that stocks mean returns generally reflect their exposure to volatility risk represented by a decreasing relationship between market price of volatility risk and forward stocks returns.

Table (6). Estimation of volatility risk price

Panel A. Estimation of risk factors

\begin{tabular}{|c|c|c|c|}
\hline & (I) & (II) & (III) \\
\hline Cste & $\begin{array}{c}-0,008 \\
(-0.4016)\end{array}$ & $\begin{array}{c}-0,001 \\
(-0,0768)\end{array}$ & $\begin{array}{c}-0,0043 \\
(-0,0772)\end{array}$ \\
\hline MKT & $\begin{array}{c}0.707 \\
13.401\end{array}$ & $\begin{array}{c}0,6874 \\
(11,665)\end{array}$ & $\begin{array}{l}0,9784 \\
(0,605)\end{array}$ \\
\hline FVIX & $\begin{array}{c}-2.432 \\
(-17.101)\end{array}$ & $\begin{array}{c}-2,195 \\
(-1,1437)\end{array}$ & $\begin{array}{c}-2,0988 \\
(-3,1437)\end{array}$ \\
\hline SMB & ( & $\begin{array}{l}0.6471 \\
(0.655)\end{array}$ & $\begin{array}{l}0.5077 \\
(8.655)\end{array}$ \\
\hline HML & - & $\begin{array}{l}-0.1712 \\
(-6,008)\end{array}$ & $\begin{array}{l}-0.5612 \\
(-0,008)\end{array}$ \\
\hline UMD & - & - & $\begin{array}{c}0.1014 \\
(2,7185) \\
\end{array}$ \\
\hline
\end{tabular}

Equation (I): $r_{t}^{i}=\alpha_{i}+\beta_{M K T}^{i} \cdot \lambda_{M K T}+\beta_{F V I X}^{i} \cdot \lambda_{F V I X}+\xi_{t}$

Equation(II): $r_{t}^{i}=\alpha_{i}+\beta_{M K T}^{i} \cdot \lambda_{M K T}+\beta_{F V I X}^{i} \cdot \lambda_{F V I X}+\beta_{S M B}^{i} \cdot \lambda_{S M B}+\beta_{H M L}^{i} \cdot \lambda_{H M L}+\xi_{t}$

Equation(III): $r_{t}^{i}=\alpha_{i}+\beta_{M K T}^{i} \cdot \lambda_{M K T}+\beta_{F V I X}^{i} \cdot \lambda_{F V I X}+\beta_{S M B}^{i} \cdot \lambda_{S M B}+\beta_{H M L}^{i} \cdot \lambda_{H M L}+\beta_{U M D}^{i} \cdot \lambda_{U M D}+\xi_{t}$

Panel B. Estimation of ex-post hedging factors of volatility FVIX

\begin{tabular}{ccccc}
\hline & & \multicolumn{3}{c}{$\beta_{\Delta V I X}$} \\
\cline { 3 - 5 } & & $\mathbf{1}$ low & $\mathbf{2}$ & $\mathbf{3}$ \\
\hline \multirow{2}{*}{$\beta_{M K T}^{i}$} & 1 low & -3.876 & -5.8766 & -5.9968 \\
& 2 & 1.5433 & -3.9954 & -1.9874 \\
& 3 high & 2.7677 & 5.009 & 3.2213 \\
\hline
\end{tabular}

Panel B represents values of hedging factors FVIX obtained from regression I.

In regression III, we notice integration of the momentum factor has no effect on the results and the estimation of FVIX remains essentially unchanged. Including the UMD factor, its risk premium remains non-signifcant and the value of FVIX exceeds -2.19 to reach -2.09 . The low momentum effect on FVIX coefficient may be explained by the low correlation between the two variables. The results on these variables show also that past returns could not improve low mean returns of stocks with high sensitivity to volatility risk $\beta_{\text {FVIX }}^{i}$. For all regressions, the FVIX coefficient decreases to reach -2.09 yet it remains significant at the $5 \%$ level. We conclude here that this the only factor of all proposed independent factors that remains statistically significant in the entire study.

Panel B of Table (6) reports values of the ex-post FVIX factors of investment portfolios creation. We notice that the values confirm the hypothesis that mean returns of portfolios 
constructed in terms of their sensitivity to risk $\beta_{\Delta V I X}^{i}$ reflect in ex-post their exposure degree to volatility risk. The ex-post value of FVIX of portfolios creation increases in a monotone fashion from portfolio 1 (with lowest $\beta_{\Delta V I X}^{i}$ ) to portfolio 3 (with the highest $\beta_{\Delta V I X}^{i}$ ). For portfolios classified in terms of past $\beta_{\Delta V I X}^{i}$ and $\beta_{F V I X}^{i}$, the values of FVIX are mixed.

Comparing our results with those reported in Table (1) which presents results on estimating volatility risk exposure and explaining the important difference in mean returns between the first and the fifth portfolio, we note that the ex-post difference of $\beta_{F V I X}^{i}$ is 10.8 compared to an ex-post difference of $\beta_{F V I X}^{i}$ of 9.11 reported in Table (1). Then, FVIX does not allow taking into account the difference of mean returns between portfolios.
In the previous sub-section, we studied the impact of volatility risk on mean returns of stocks classified in terms of their sensitivity to variations in systemic volatility risk. In this section, we mainly examine idiosyncratic component of volatility using stocks classified in terms of their sensitivity to this type of volatility. Then, if idiosyncratic volatility risk is an omitted variable from total volatility risk, standards estimation models based essentially on systemic volatility should under-evaluate portfolios classified in terms of idiosyncratic volatility as these models do not include their exposure to this type of volatility risk.

\subsection{Investment Strategy}

Idiosyncratic volatility risk is estimated by Fama and French model. It is determined through the square root of residual risk variation: $\sqrt{\operatorname{var} \xi_{t}^{i}}$ obtained from the following regression:

\section{Idiosyncratic Volatility}

$$
r_{t}^{i}=\alpha_{i}+\beta_{M K T}^{i} \cdot \lambda_{M K T}+\beta_{S M B}^{i} \cdot \lambda_{S M B}+\beta_{H M L}^{i} \cdot \lambda_{H M L}+\xi_{t}
$$

Some economic theories suggest that idiosyncratic volatility should be positively related to expected returns. If investors demand compensation for not being able to diversify risk, then agents will demand a premium for holding stocks with high idiosyncratic volatility. [8] In order to study the impact of this component on stocks returns, we create investment portfolios based on a study period of $\mathrm{L}$ months, a portfolios creation period on $\mathrm{M}$ months and a detention period of $\mathrm{N}$ months. We describe this $\mathrm{L} / \mathrm{M} / \mathrm{N}$ strategy as follows: during each month $\mathrm{t}$, we estimate idiosyncratic volatility using daily data that separate the $\mathrm{t}-\mathrm{L}-\mathrm{M}$ period from $\mathrm{t}-\mathrm{L}$ period using regression (6). In terms of $t$, we classify stocks according to their exposure to idiosyncratic volatility risk and then we construct investment portfolios. Detention period of these portfolios is evaluated in $\mathrm{N}$ months in order to analyse volatility risk.

Our study refers to $1 / 0 / 1$ strategy for which we simply classify stocks into portfolios according to their idiosyncratic volatility risk levels of daily returns achieved during the past month and we retain this portfolio for a month.

\subsection{Total and Idiosyncratic Volatility}

Our study consists in analyzing mean returns of stocks portfolios classified according to their sensitivity to the different volatility variations. Panel A of Table (7) reports variations of total volatility risk regardless of systemic risk. Our strategy is the $1 / 0 / 1$. Following [3], we notice that results of mean returns of portfolio 1 (consisting of stocks with the lowest total volatility) increases to reach 0.003 per month. For Portfolio (2) increase of returns is more significant and reaches 0.008 . Mean returns of portfolio 3 (consisting of stocks with the highest volatility) is 0.006 per month. Value of $\alpha$ of the FF model presented in the last column of Table (7) of portfolio 3 is 0.006 and is highly significant. The difference in $\alpha$ between portfolios 3 and 1 is 0.003 per month. Against all this, we conclude that the more stocks are sensitive to total risk, the much lower their mean returns are. Panel B of Table (7) reports variations of mean returns of stock portfolios classified according to their sensitivity volatility idiosyncratic risk and not according to total risk. We notice that the obtained results are similar to those of panel A. The difference of mean gross returns between portfolios 3 and 1 is 0.003 . The $\alpha$ of the FF model is also unable to adequately take into account variations of the idiosyncratic component of risk as the difference in $\alpha$ between portfolios 3 and 1 is $0.002 \%$ per month.

The BM and size component score moreover interesting results. We note that stocks with the lowest sensitivity to idiosyncratic risk are generally stocks whose market capitalisation is high and the BM is low while stocks with the highest sensitivity to idiosyncratic risk are stocks whose market capitalisation is low and the BM is high. Weighted risk of the FF model assumes that stocks of portfolio 3 reached important mean returns while obtained mean returns are only 0.006 . These results are confusing, in particular the low mean return of portfolio 3. This may be explained the fact that this portfolio represents only $30 \%$ of stocks classified according to idiosyncratic volatility, which a low market portion and cannot represent the effect of idiosyncratic volatility on stocks returns. The question to be asked, then, is: will this result be the same if we consider the unconditional risk factors studied previously?

To answer this question, in the following section we will examine the impact of idiosyncratic volatility of factors which the literature identified as potential risk factors. 
Table (7). A study of volatility effect

Panel A. Portfolios classified in terms of total volatility

\begin{tabular}{|c|c|c|c|c|c|c|}
\hline portfolios & Mean $(* 100)$ & Standard Deviation & Size & BM & Alpha CAPM & Alpha F-F \\
\hline 1 & 0.0325 & 0.00881 & 258972,9 & 0,389923 & $\begin{array}{c}0.00565 \\
(2.664)\end{array}$ & $\begin{array}{c}0.00346 \\
(2,785)\end{array}$ \\
\hline 2 & 0.0862 & 0.00443 & 248483 & 0,310475 & $\begin{array}{l}0.00218 \\
(0.0443)\end{array}$ & $\begin{array}{l}0.00131 \\
(0.0098)\end{array}$ \\
\hline 3 & 0,0677 & 0.00377 & 264190,9 & 0,272901 & $\begin{array}{c}0,00873 \\
(3.781)\end{array}$ & $\begin{array}{c}0,00344 \\
(1.886)\end{array}$ \\
\hline $3-1$ & 0.0352 & - & - & - & 0.00308 & 0.00002 \\
\hline
\end{tabular}

Panel B. Portfolios classified in terms of idiosyncratic volatility

\begin{tabular}{|c|c|c|c|c|c|c|}
\hline Portfolios & Mean $(* 100)$ & Standard Deviation & Size & BM & Alpha CAPM & Alpha F-F \\
\hline 1 & 0.0663 & 0.00051 & 290000 & 0,370151 & $\begin{array}{c}0.00223 \\
(4.211)\end{array}$ & $\begin{array}{c}0.00865 \\
(1.057)\end{array}$ \\
\hline 2 & 0.0688 & 0.00884 & 53315,67 & 0,230477 & $\begin{array}{l}0.0121 \\
(1.897)\end{array}$ & $\begin{array}{c}0.00131 \\
(2.865)\end{array}$ \\
\hline 3 & 0,0244 & 0.00066 & 182026 & 0,384347 & $\begin{array}{c}0,01631 \\
(3.002)\end{array}$ & $\begin{array}{c}0,00774 \\
(0.544)\end{array}$ \\
\hline $3-1$ & -0.0419 & & & & 0.4104 & \\
\hline
\end{tabular}

\subsubsection{Size Effect}

In order to study interaction between size effect and stocks sensitivity to idiosyncratic volatility, we introduce size effect by constructing stock portfolios according to their market capitalization size. Next, we classify size of stocks of each portfolio according to idiosyncratic volatility. Finally, for each size level we end up with 3 portfolios; the first is the one with the lowest idiosyncratic volatility and the third is the one with the highest idiosyncratic volatility.

Table (8). Values of $\alpha$ of portfolios constructed according to idiosyncratic volatility

\begin{tabular}{cccc}
\hline Idiosyncratic volatility & $\mathbf{1}$ & $\mathbf{2}$ & $\mathbf{3}$ \\
\hline \multirow{2}{*}{ Size 1 low } & -0.00447 & 0.0009 & -0.00127 \\
& $(-2.6643)$ & $(1.443)$ & $(-4.415)$ \\
2 & 0.00324 & 0.00761 & 0.02341 \\
& $(2,5663)$ & $(2,7063)$ & $(2,7063)$ \\
\multirow{3}{*}{ high } & 0.00102 & 0.00543 & 0.00224 \\
& $(1.042)$ & $(0.0241)$ & $(4.0071)$ \\
Size effect & -0.00527 & 0.00139 & -0.00982 \\
& $(-1.9873)$ & $(0.5703)$ & $(-2.785)$ \\
BM effect & -0.00376 & -0.00761 & -0.00556 \\
& $(-2,6652)$ & $(-0,556)$ & $(-1,7223)$ \\
Coskewness effect & -0.00776 & -0.0043 & -0.00358 \\
& $(-3.224)$ & $(-1.466)$ & $(-4.785)$ \\
\hline
\end{tabular}

Table (8) presents the results of the investment strategies $1 / 0 / 1$. We note that for portfolio size level, the portfolio with the highest idiosyncratic volatility is that with the lowest $\alpha$ value of the FF model. This result does not necessarily concern stocks with the lowest market capitalisation. The value of $\alpha$ of the FF model for portfolio 2 is 0.02 and represents the highest value compared to that of portfolio 3 .
This result is highly significant with a t-statistic of 2.7.

By contrast, the difference in $\alpha$ of the FF model for the portfolios with lowest and highest market capitalisation is low and non-significant. We may conclude that it is not the stocks with the lowest market capitalisation that affect market volatility. Then, market capitalisation could not explain low returns of stocks with high idiosyncratic volatility.

\subsubsection{Book to Market Effect}

It is generally admitted that growth-oriented firms with the highest $\mathrm{BM}$ achieve the highest mean returns by contrast to value-oriented firms with the lowest $\mathrm{BM}$ whose mean returns are the lowest. More precisely, BM effect seems to explain idiosyncratic volatility. High-idiosyncratic volatility portfolios should essentially consist of growth-oriented stocks with the highest BM. Table (8) reports the results of investment strategies $1 / 0 / 1$ which consist in creating stock portfolios classified according to the importance of their BM and in classifying stocks of each portfolio according to idiosyncratic volatility value. Line 3 of table (8) indicates, contrary to previous results, that stocks of portfolios with the lowest $\mathrm{BM}$, for each idiosyncratic level, the highest FF $\alpha$ reaching -0.003 for portfolio 1 and -0.005 for portfolio 3 . The difference in FF $\alpha$ for portfolios with lowest and highest $\mathrm{BM}$ is -0.002 . This result is statistically non-significant. Against these results, we may conclude that BM has no effect on stocks' idiosyncratic volatility nor on their mean returns.

\subsubsection{Coskewness Effect}

We have shown previously referring the works of [4] that stocks with coskewness coefficient achieve the highest forward returns. stocks that do badly when volatility increases tend to have negatively skewed returns over intermediate horizons, while stocks that do well when 
volatility rises tend to have positively skewed returns[9]We propose here that the stocks with high idiosyncratic volatility should score a positive coskewness coefficient as mean returns achieved by these stocks are low.

Our study consists in estimating coskewness coefficient using the following equation:

$$
\beta_{S K D_{i}}=\frac{E\left[\varepsilon_{i, t+1} \varepsilon_{M, t+1}^{2}\right]}{\sqrt{E\left[\varepsilon_{i, t}^{2}\right] E\left[\varepsilon_{M, t}^{2}\right]}}
$$

Where $\varepsilon_{i, t+1}=r_{i, t+1}-a i-\beta_{i} r_{m, t+1}$ is a residual of the regression of stocks returns surplus on market returns.

The results in Table (9) lead us to conclude that exposure to coskewness effect does not particularly explain the relationship between stocks sensitivity to idiosyncratic volatility and their achieved mean returns. We notice that the difference of $\mathrm{FF} \alpha$ for portfolios with the lowest and highest coskewness coefficient is almost zero.

\subsubsection{Study of the Momentum Effect}

Several studies[6],[8] showed that the momentum effect described by [3] is asymmetric as the negative effect scored for decreasing stocks is higher than the positive effect scored for increasing stocks. Remarkably, the lowest past returns stocks are stocks which represent higher sensitivity to idiosyncratic volatility. It is clear that stocks of past winning stocks present also higher idiosyncratic volatility, yet it is the past losing stocks that are overestimated during evaluation of returns achieved by stocks with the highest idiosyncratic volatility.

In this section, we study the relationship between idiosyncratic volatility and the momentum effect. To this end, a series of tested is conducted. The results are presented in Table (9). Panel A presents the values of FF $\alpha$ for the different portfolios classified according to idiosyncratic volatility and their past returns.

Our analysis consists of studying characteristics of momentum portfolios in different study periods of past returns, in particular our 1-month, 6-month and 12-month span study. Table (9) reports the obtained results. We note that these results are similar to the previous ones. The value of FF $\alpha$ in a 1-month period is monotone and increasing, in particular $\alpha$ of the $3^{\text {rd }}$ portfolio, and is 0.006 and the difference in $\alpha$ between the 3 rd portfolio and the 1st portfolio is 0.001 . These results are statistically significant.

Table(9). Study of momentum effect on $\alpha$ of portfolios classified according to idiosyncratic volatility.

Panel A. Study of Momentum effect

\begin{tabular}{|c|c|c|c|c|}
\hline & 1 low & 2 & 3 high & $3-1$ \\
\hline 1 month & $\begin{array}{c}0.00494 \\
(2.642)\end{array}$ & $\begin{array}{l}0.00431 \\
(2.224)\end{array}$ & $\begin{array}{c}0.00664 \\
(3.987)\end{array}$ & 0.0017 \\
\hline 6 month & $\begin{array}{c}0.00154 \\
(2,4303)\end{array}$ & $\begin{array}{c}0.00291 \\
(1,703)\end{array}$ & $\begin{array}{c}0.00442 \\
(2,665)\end{array}$ & 0.00288 \\
\hline 12 month & $\begin{array}{c}-0.00164 \\
(-1,543) \\
\end{array}$ & $\begin{array}{c}0.00762 \\
(1.897)\end{array}$ & $\begin{array}{c}0.00752 \\
(2.683)\end{array}$ & 0.00916 \\
\hline
\end{tabular}

Panel B. Study of the 12-month period.

\begin{tabular}{ccccc}
\hline & 1 low & $\mathbf{2}$ & $\mathbf{3}$ high & $\mathbf{3 - 1}$ \\
\hline \multirow{2}{*}{ loser 1} & -0.00224 & -0.00246 & 0.00327 & 0 \\
& $(-2,776)$ & $(1,442)$ & $(1,876)$ & 0,00551 \\
\multirow{2}{*}{2} & -0.00143 & 0.001 & 0.00262 & 0 \\
& $(-1,523)$ & $(1.247)$ & $(2.021)$ & 0,00305 \\
\multirow{2}{*}{ winner 3 } & 0.00254 & 0.00142 & 0.00365 & 0,00111 \\
& $(2,082)$ & $(1.393)$ & $(2.677)$ & \\
\hline
\end{tabular}

For a 6-month study, the difference in $\alpha$ between the $3^{\text {rd }}$ portfolio and the $1^{\text {st }}$ portfolio is 0.002 . This difference is even more important and reaches 0.009 for the 12-month study. These statistically-significant results lead us to conclude that the momentum effect could not explain idiosyncratic volatility effect on stocks mean returns.

Panel B represents values of FF $\alpha$ for portfolios classified in terms of past 12 months and stocks sensitivity to idiosyncratic volatility. We note that $\mathrm{FF} \alpha$ values for these different portfolios are similar to those obtained in Panel A of Table (9). Several important facts can be concluded from these results.

First, We notice that low returns of idiosyncratic volatility are more observable for losing stocks than for winning stocks. The $\alpha$ difference between the $3^{\text {rd }}$ portfolio and the $1^{\text {st }}$ portfolio is 0.005 for the losing stocks and 0.001 for the winning stocks. Second, this tendency of momentum effect remarkable for losing stocks cannot represent low returns in case of high idiosyncratic volatility, as idiosyncratic volatility value is significant for all types stock returns portfolios, in particular for low mean returns portfolios. This is whether stocks are winning or losing. A remarkable effect is also presence of asymmetry in the momentum effect. We note for the first idiosyncratic volatility portfolio that $\alpha$ values of extreme winning and losing portfolios are symmetric. For the first level of portfolios with the lowest idiosyncratic volatility, $\alpha$ for the losing portfolio is -0.0022 where as that of the winning portfolio is 0.0025 . For the second level of portfolios, $\alpha$ for the losing portfolio is -0.002 where as that of the winning portfolio is 0.001 . The higher idiosyncratic volatility is, the more "skewed" the momentum effect becomes for extreme stocks with low mean returns and high idiosyncratic volatility. This result leads us to conclude that the most profitable momentum strategy consists in selling past losing stocks with the highest idiosyncratic volatility and purchasing past winning stocks with the highest idiosyncratic volatility.

\subsection{Total Volatility and Idiosyncratic Volatility}

We test here the alternative that high negative returns of stocks with high idiosyncratic volatility result from their high exposure degree to volatility variations. To this end, we classify stocks first according to the coefficient of their sensitivity to volatility risk variations $\beta_{\triangle V I X}^{i}$ and second according to their volatility estimated by hedging factors FVIX. Choice of $\beta_{\Delta V I X}^{i}$ as an estimation parameter of volatility risk is supported by the previously obtained result 
which indicates that stocks with the highest past $\beta_{\Delta V I X}^{i}$ are generally the stocks that are most exposed to hedging factors of volatility.

Table (10) reports the results of mean values of FF $\alpha$ for each level of $\beta_{\Delta V I X}^{i}$ portfolio and for each level of FVIX.

Table (10). Study of the effect of idiosyncratic volatility on volatility risk

Panel A. Study of $\alpha$ of FF-3

\begin{tabular}{ccccc}
\hline Idiosyncratic volatility & $\mathbf{1}$ low & $\mathbf{2}$ & $\mathbf{3}$ high & $\mathbf{3 - 1}$ \\
\hline \multirow{2}{*}{ volatility risk } & -0.004672 & 0.00243 & 0.00564 & \multirow{2}{*}{0.01031} \\
\hline
\end{tabular}

Panel B. Study of FVIX factors

\begin{tabular}{|c|c|c|c|c|}
\hline Idiosyncratic volatility & 1 low & 2 & 3 high & $3-1$ \\
\hline$\beta_{\Delta V I X}^{i} \quad 1$ low & $\begin{array}{l}-0.00658 \\
(-2.8863)\end{array}$ & $\begin{array}{c}-0.00539 \\
(-1.903)\end{array}$ & $\begin{array}{c}0.00122 \\
(-2.0285)\end{array}$ & 0.00780 \\
\hline 2 & $\begin{array}{l}-0.00542 \\
(-1,7852)\end{array}$ & $\begin{array}{l}0.00261 \\
(2,9556)\end{array}$ & $\begin{array}{l}0.00664 \\
(1,8823)\end{array}$ & 0.01196 \\
\hline 3 high & $\begin{array}{l}-0.00442 \\
(-1.224)\end{array}$ & $\begin{array}{l}0.00247 \\
(0.466)\end{array}$ & $\begin{array}{l}-0.00358 \\
(-2.675)\end{array}$ & -0.00104 \\
\hline
\end{tabular}

According to Panel A of table (10), studying exposure degree of stocks to volatility, $\alpha$ value corresponding to the difference between portfolios (1-3) is 0.0103 compared to 0.086 in Table (6) when systemic volatility is not taken into account. This result leads us to conclude that the coefficient of sensitivity to volatility risk variations $\beta_{\Delta V I X}^{i}$ takes only a part of low mean reports stocks with high idiosyncratic volatility.

Panel B presents values of $\alpha$ obtained for portfolios constructed according to hedging factors FVIX and sensitivity factors $\beta_{\Delta V I X}^{i}$. We notice that for the first portfolios with the lowest $\beta_{\Delta V I X}^{i}, F V I X$ value is monotone and increasing with a negative value equal to (-0.006) for stocks with the lowest idiosyncratic volatility and a positive value $(0.001)$ for stocks with the highest idiosyncratic volatility. Moreover, we note that the hedging factors FVIX cannot explain the stock portfolio with the highest $\beta_{\Delta V I X}^{i}$. A fact which leads us to conclude that low returns of stocks with the highest idiosyncratic volatility can be explained only for stocks exposed to volatility negative shocks.

\section{Conclusion}

One the most famous puzzles in the literature is excessive market volatility. Nevertheless, in reality we notice that volatility has more than a simple excessive component to it. It presents an important component, which is that of asymmetry. This is true, knowing that its reaction to a shock on returns differs according to shock sing.

Determinants of stock market variations help better define volatility characteristics. Effect of stocks' exposure degree to volatility is understood as a determining factor of Tunisian stock market volatility, defined in terms of hedging factors of volatility risk or in terms of "idiosyncratic volatility" as suggested by [5]. Our results indicate that stocks sensitivity to price shocks results from an excessive component of volatility. We notice in particular that risk-averse investors ask for a premium to compensate for a detention risk of stocks with high sensitivity to volatility risk [3][10]. we find that stocks with high sensitivities to innovations in volatility have low average returns. In addition, we find that stocks with high idiosyncratic volatility relative to the Fama and French (1993) model have low average returns. These low average returns to stocks with high idiosyncratic volatility cannot be explained by exposures to size, book-to-market and momentum effects.

The effect also persists in volatile and stable periods, and is robust to considering different formation and holding periods as long as one year. Although we argue that volatility risk is a new systematic factor, exposure to volatility risk accounts for very little of the anomalous low returns of stocks with high idiosyncratic volatility. Hence, the expected return patterns found by sorting on idiosyncratic volatility present something of a puzzle.

\section{References}

[1] J. Campbell and Hentshel. L (1992), "No news is Good news: An asymmetric model of changing volatility in stock return", Journal of financial economics, vol 3, pp 281- 318

[2] L. Glosten, R. Jagannathan and D. Runkle (1993), "On the relation between the expected value and the volatility of the nominal excess return on stock", Journal of fianance 48,5, pp 1779-1801.

[3] A. Ang, R. Hodrick, X. Yuhang and Z. Xiaoyan (2004), "The cross section of volatility and expected returns", NBER working paper series.

[4] C. Harvey and A. Siddique (2000), "Conditional skewness in asset pricing Tests”, Journal of finance, vol 3, pp 1263- 1295.

[5] E. Fama and K. French (1996), "Multifactor explanations of asset pricing anomalies", Journal of Finance, Vol 51, pp 55-84.

[6] V. Huang, L. Qianqiu, S. Rhee and L. Zhang (2011), "Another Look at Idiosyncratic Volatility and Expected Returns", Journal Of Investment Management (JOIM), Fourth Quarter 2011.

[7] V. Acharya, H. Almeida and M. Campello (2012) , "Aggregate Risk and the Choice between Cash and Lines of Credit", CEPR Discussion Paper No. DP8913

[8] R F. Stambaugh, J. Yu and Y. Yuan (2012), “Arbitrage Asymmetry and the Idiosyncratic Volatility Puzzle" NBER Working Paper No. w18560.

[9] S.A. Anthonisz (2012), "Asset Pricing with Partial-Moments",Journal of Banking and Finance, Vol. 36, No. 7, pp 214-221. 
[10] D. Brown and M. Ferreira (2003), "The information in the idiosyncratic volatility of small firms", Working paper, University of Wisconsin-Madison.

[11] E. Fama and J. MacBeth (1973), "Risk return and equilibrium: Empirical tests", Journal of political economy 71,607-636.

[12] N. Jegadeesh and S. Titman (2001), "Profitability of momentum strategies: An evaluationof alternative explanations", Journal of Finance, Vol 56, pp 699-720
[13] M. Rockinger and E. Jondeau (2000), "Conditional volatility, skewness and kurtosis: existence and persistence", Working paper

[14] V. Torous, and Yan (2004), “On Predicting Stock Return whith nearly integrated explanatory variables, Journal of Business", Vol 77,pp 973-966. 